Quim. Nova, Vol. 36, No. 5, 686-690, 2013

\title{
PREPARATIVE SEPARATION AND PURIFICATION OF BUFADIENOLIDES FROM ChanSu BY HIGH-SPEED COUNTER-CURRENT CHROMATOGRAPHY COMBINED WITH PREPARATIVE HPLC
}

\author{
Jialian Li and Yongqing Zhang \\ College of Pharmacy, Shandong University of Traditional Chinese Medicine, Jinan, Shandong, 250355, P. R. China \\ Yunliang Lin, Xiao Wang, Lei Fang* and Yanling Geng \\ Shandong Analysis and Test Center, Shandong Academy of Sciences, 19 Keyuan Street, Jinan, Shandong, 250014, P. R. China \\ Qinde Zhang \\ Shandong College of Traditional Chinese Medicine, Laiyang, Shandong, 265200, P. R. China
}

Recebido em 13/9/12; aceito em 6/12/12; publicado na web em 4/4/13

\begin{abstract}
Eight bufadienolides were successfully isolated and purified from ChanSu by high-speed counter-current chromatography (HSCCC) combined with preparative HPLC (prep-HPLC). First, a stepwise elution mode of HSCCC with the solvent system composed of petroleum ether-ethyl acetate-methanol-water (4:6:4:6, 4:6:5:5, v/v) was employed and four bufadienolides, two partially purified fractions were obtained from $200 \mathrm{mg}$ of crude extract. The partially purified fractions III and VI were then further separated by prepHPLC, respectively, and another four bufadienolides were recovered. Their structures were confirmed by ESI-MS and ${ }^{1} \mathrm{H}-\mathrm{NMR}$ spectra.
\end{abstract}

Keywords: high-speed counter-current chromatography; bufadienolides; preparative HPLC.

\section{INTRODUCTION}

Venenum bufonis, also called ChanSu, is prepared from dried toad secretions derived from either Bufo bufo gargarizans Cantor or Bufo melsanostictus Schneider ${ }^{1}$ and has been widely used as a cardiotonic, diuretic, anodyne and antineoplastic agent. ${ }^{2}$ Phytochemical studies have revealed that bufadienolides are contained in the vast majority of fat-soluble compounds in $\mathrm{ChanSu}$ which are also the major bioactive constituents. To date, more than 70 bufadienolides have been isolated from ChanSu, including bufalin, cinobufagin, resibufogenin and so on. ${ }^{2}$ Recent pharmacological studies have indicated that bufadienolides can induce apoptosis, inhibit cell proliferation, promote cell differentiation, reverse drug resistance, restrain neovacularization and enhance the immune system. ${ }^{3}$ Furthermore, bufadienolides have been shown to exhibit significant inhibitory activities against different kinds of human cancer cells, including myeloid leukemia and prostate cells. ${ }^{4,5}$ Considering these beneficial biological properties and broad applications of bufadienolides, it is necessary to establish an efficient method of obtaining these compounds from $\mathrm{ChanSu}$ with high purities and in large quantities for further pharmacological research.

However, the conventional methods using column chromatography employed to separate bufadienolides are often tedious, time consuming, while requiring multiple chromatographic steps and large amounts of reagents. ${ }^{6,7}$ High-speed counter-current chromatography (HSCCC), as a liquid-liquid partition chromatographic technique, has various advantages, such as no irreversible adsorption, large volumes of sample injection, a simple process and low cost. HSCCC has been successfully applied to prepare various types of natural products. ${ }^{8-11}$ $\mathrm{Ma}$ and co-researchers have isolated several bufadienolides from ChanSu using HSCCC. However, the separation process lasted more than $11 \mathrm{~h} .{ }^{12}$ Hence, it is necessary to explore a more powerful and efficient method of separating bufadienolides at large quantities in a shorter time. Preparative high-performance liquid chromatography (prep-HPLC) is becoming a powerful tool for the isolation of natural products in virtue of its excellent efficiency and high recovery. When prep-HPLC is coupled with HSCCC, its disadvantages including trial

*e-mail: fleiv@163.com pretreatment of sample and overloaded columns, caused by plentiful raw sample that could be compensated by HSCCC. ${ }^{13}$ However, few reports have been published on the separation and purification of bufadienolides from ChanSu by HSCCC combined with prep-HPLC.

This paper reports a high-efficiency method developed for the separation and purification of bufadienolides from ChanSu by HSCCC combined with prep-HPLC. Eight bufadienolides were successfully obtained and identified as arenobufagin (1), bufotalin (2), 19-oxo-cinobufagin (3), cinobufotalin (4), bufalin (5), cinobufagin (6), resibufogenin (7) and hellebrigenin-3-hemisuberate $(\mathbf{8})$ with purities of 97.7, 97.0, 99.0, 99.8, 99.5, 99.1, 98.5 and 96.1\%, respectively. Their chemical structures are shown in Figure 1.

\section{EXPERIMENTAL}

\section{Apparatus}

The HSCCC instrument used in this study was a model GS10A-2 high-speed counter-current chromatograph (Beijing Emilion Science $\&$ Technology Co., Beijing, China), equipped with 2 multilayer coil separation columns connected in series (diameter of tube $=1.6 \mathrm{~mm}$, total volume $=330 \mathrm{~mL}$ ) and a $20 \mathrm{~mL}$ sample loop. The $\beta$ values of the multilayer coil varied from 0.5 at the internal terminal to 0.8 at the external terminal $(\beta=r / R$, where $r$ is the rotation radius or the distance from the coil to the holder shaft, and $R(R=8 \mathrm{~cm})$ is the revolution radius or the distance between the holder axis and central axis of the centrifuge). A speed controller can regulate the revolution speed within a range of between 0 and $1000 \mathrm{rpm}$. A model NS-1007 constant-flow pump (Beijing Emilion Science \& Technology Co., Beijing, China) was used to deliver the two-phase solvent system, a model 8823A-UV detector (Beijing Emilion Science \& Technology Co., Beijing, China) to monitor the continuous effluent, and a model 3057 portable recorder (Yokogawa, Sichuan Instrument Factory, Chongqing, China) to draw the chromatogram.

Preparative HPLC was carried out on a Shimadazu LC-6AD instrument equipped with a SPD-10A detector, and a YMC-Pack ODS-A column $(250 \times 10 \mathrm{~mm}$, i.d., $5 \mu)$. The analytical HPLC system employed throughout this study consisted of a Waters 600 


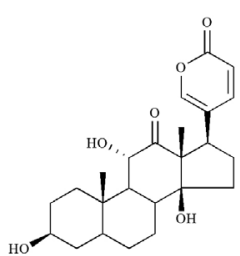

1



4

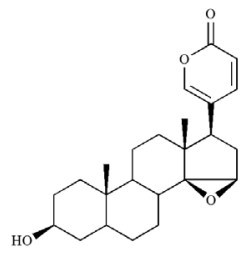

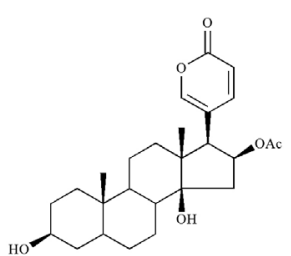

2

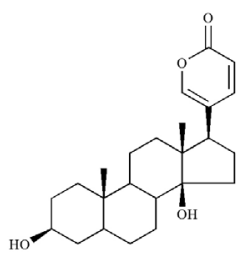

5

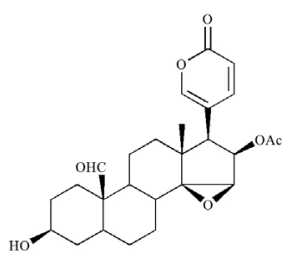

3

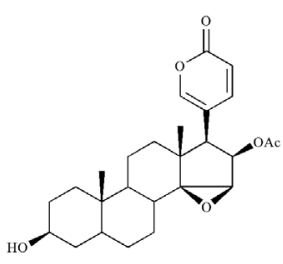

6
Figure 1. Chemical structures of the eight bufadienolides isolated from ChanSu

pump, a Waters 600 Multisolvent Delivery, a Waters 996 diode-array detector (DAD), a Waters 600 system controller and a Millennium 32 workstation (Waters, Milford, USA).

\section{Materials}

Petroleum ether $\left(60-90^{\circ} \mathrm{C}\right)$, methanol, chloroform, ethyl acetate and acetic acid were all of analytical grade (Dame Chemical Factory, Tianjin, China). Acetonitrile used for HPLC analysis was of chromatographic grade (Siyou Special Reagent Factory, Tianjin, China). Reverse osmosis Milli-Q water (Millipore, USA) was used for all solutions and dilutions.

Venenum bufonis was purchased from a local drug store and identified as the skin secretions of Bufo bufo gargarizans Cantor by Dr. Li jia (College of Pharmacy, Shandong University of Traditional Chinese Medicine).

\section{Sample preparation}

The dried materials of ChanSu (80 g) were powdered and extracted with methanol 3 times ( $1 \mathrm{~L} \times 3$ ) (each time $1 \mathrm{~h}$ ). The extract was then combined and concentrated to yield $24.5 \mathrm{~g}$ of residue. The residue was dissolved in $300 \mathrm{~mL}$ of distilled water and extracted 3 times with chloroform $(500 \mathrm{~mL} \times 3)$. Finally, around $16.3 \mathrm{~g}$ of chloroform residue was obtained and stored in a refrigerator for subsequent HSCCC separation.

\section{Selection of two-phase solvent system}

The selection of the two-phase solvent system is a crucial factor for successful separation by HSCCC. The two-phase solvent system was selected according to the partition coefficients $\left(K_{D}\right)$ of the target compound. The $K_{D}$ value is defined as the concentration of the compound in the stationary phase $\left(C_{\mathrm{SP}}\right)$ divided by the concentration of the compound in the mobile phase $\left(C_{\mathrm{MP}}\right): K_{D}=C_{\mathrm{SP}} / C_{\mathrm{MP}}$. In this study, the upper layer was used as the stationary phase throughout the HSCCC separation where the $K_{D}$ value was determined by HPLC analyses as following: ${ }^{14} 1 \mathrm{~mL}$ of each phase of the equilibrated two-phase solvent system was added to a test tube and a suitable amount of sample placed into the tube. The tube was then shaken vigorously to mix the solution thoroughly. After the equilibration was established, an equal volume of each phase was analyzed by HPLC to obtain the partition coefficients. The $K_{D}$ value was calculated by the following equation: $K_{D}=A_{\mathrm{U}} / A_{\mathrm{L}}\left(A_{\mathrm{U}}\right.$, the peak area of the target compound in the upper phase; $A_{\mathrm{L}}$, the area in the lower phase). ${ }^{15}$

\section{Preparation of two-phase solvent system and sample solution}

The HSCCC experiments in the present study were performed with a two-phase solvent system of petroleum ether-ethyl acetatemethanol-water with the volume ratios of 4:6:4:6 (v/v) and 4:6:5:5 (v/v). Solvent mixture was thoroughly equilibrated in a separation funnel by repeated vigorous shaking at room temperature. The two phases were then separated shortly before use. The upper phase was used as the stationary phase, while the lower phase was used as the mobile phase. The sample solution was prepared by dissolving 200 $\mathrm{mg}$ of the dried extract in $3 \mathrm{~mL}$ mixture solution of lower phase and upper phase $(1: 1, \mathrm{v} / \mathrm{v})$ of the solvent system $(4: 6: 4: 6, \mathrm{v} / \mathrm{v})$.

\section{HSCCC separation}

In HSCCC separation, the entire column was first filled with the upper phase. Then the lower phase was pumped into the head end of the column at a flow rate of $2.0 \mathrm{~mL} / \mathrm{min}$, while the apparatus was rotated at $850 \mathrm{rpm}$. After the establishment of hydrodynamic equilibrium, the sample solution was injected through the sample port. In the stepwise elution, after 220 min of elution using the solvent system (4:6:4:6, v/v), the mobile phase was switched to the second solvent system (4:6:5:5, v/v) from 220-400 min. The effluent of the column was continuously monitored by a UV detector at $296 \mathrm{~nm}$, and each peak fraction was manually collected according to the elution profile. After the separation was complete, the solvents in the column were pushed out with nitrogen gas and the retention of stationary phase was computed.

\section{Preparative HPLC purification procedure}

Each partially purified fraction of HSCCC separation was further purified by prep-HPLC. Prep-HPLC purification was performed on a YMC-Pack ODS-A column $(250 \times 10 \mathrm{~mm}$, i.d., $5 \mu)$ at room temperature and the flow rate was set at $2.5 \mathrm{~mL} / \mathrm{min}$. The mobile phase was acetonitrile- $0.3 \%$ aqueous acetic acid $(35: 65, \mathrm{v} / \mathrm{v})$ for fraction III, while the mobile phase was acetonitrile- $0.3 \%$ aqueous acetic acid $(45: 55, \mathrm{v} / \mathrm{v})$ for fraction VI. The effluent was monitored at 296 $\mathrm{nm}$ and the peak fractions collected according to the chromatogram.

\section{Analysis and identification of HSCCC and prep-HPLC fractions}

The crude sample and each fraction from the HSCCC separation and prep-HPLC purification were analyzed by HPLC with a Inertsil ODS-3 $\mathrm{C}_{18}$ column $(250 \times 4.6 \mathrm{~mm}$, i.d., $5 \mu)$. Flow rate, detection wavelength and column temperature were set at $1.0 \mathrm{~mL} / \mathrm{min}, 296 \mathrm{~nm}$ and room temperature, respectively. The mobile phase was composed of acetonitrile and $0.3 \%(\mathrm{v} / \mathrm{v})$ aqueous acetic acid in gradient elution as follows: 0-8 min, using a constant elution (42\% acetonitrile); 8-32 min, linear change from 42 to $50 \%$ acetonitrile; $32-35$ min, using a constant elution (50\% acetonitrile). 
Table 1. Partition coefficients $\left(K_{D}\right)$ of six bufadienolides

\begin{tabular}{ccccccccc}
\hline Solvent system (petroleum ether -ethylacetate-methanol-water) & $K_{1}$ & $K_{2}$ & $K_{4}$ & $K_{5}$ & $K_{6}$ & $K_{8}$ \\
\hline $5: 5: 5: 5$ & 0.36 & 0.23 & 0.28 & 0.55 & 0.85 & 0.48 \\
$5: 5: 4: 6$ & 0.48 & 0.75 & 0.95 & 2.14 & 3.94 & 2.11 \\
$4: 6: 4: 6$ & 0.98 & 1.52 & 2.05 & 3.55 & 6.32 & 5.99 \\
$4: 6: 5: 5$ & 0.58 & 0.66 & 0.78 & 0.89 & 2.06 & 1.55 \\
\hline
\end{tabular}

The identification of the 8 compounds was carried out by electrospray ionization mass spectrometry (ESI-MS) on an Agilent 1100/ MS-G1946 (California, USA) and ${ }^{1} \mathrm{H}$ NMR spectra on a Varian600NMR spectrometer (Varian, Palo Alto, CA, USA) with DMSO as solvent and tetramethylsilane (TMS) as internal standard.

\section{RESULTS AND DISCUSSION}

\section{Selection of HSCCC conditions}

The selection of a suitable two-phase solvent system is a critical step for successful HSCCC separation. To achieve successful separation using HSCCC, the suitable solvent system should provide an ideal partition coefficient range $\left(K_{D}, 0.5-2\right)$ for bufadienolides. ${ }^{16,17}$ Excessively large $K_{D}$ values $\left(K_{D}>2\right)$ tend to produce excessively broad peaks and lead to extended elution times, while $K_{D}$ values $\left(K_{D}\right.$ $<0.5)$ that are too small often result in loss of peak resolution. In our research, the solvent system of petroleum ether-ethyl acetate-methanol-water was chosen and the $K_{D}$ values in different solvent systems are summarized in Table 1.

As shown in Table 1, compounds 1, 2, and 4 showed the suitable $\mathrm{K}_{\mathrm{D}}$ values in the solvent system of petroleum ether-ethyl acetatemethanol-water (4:6:4:6, v/v), while compound 5, 6 and 8 had the suitable $\mathrm{K}_{\mathrm{D}}$ values in the solvent system of petroleum ether-ethyl acetate-methanol-water (4:6:5:5, v/v). Thus, a stepwise elution mode of HSCCC was developed to achieve good separation. However, the preliminary test indicated that bufadienolides $\mathbf{1}, \mathbf{2}, \mathbf{5}$ and $\mathbf{8}$ could be excellently separated, while bufadienolides $\mathbf{3}$ and 4, $\mathbf{6}$ and $\mathbf{7}$ were eluted together as one peak, respectively. For this reason, prep-HPLC was utilized to further purify bufadienolides $\mathbf{3}$ and 4, $\mathbf{6}$ and 7. Consequently, a combination of both HSCCC and prep-HPLC was established for the separation and purification of bufadienolides from ChanSu. First, $200 \mathrm{mg}$ of the sample was purified by HSCCC using a stepwise elution mode with the solvent system of petroleum etherethyl acetate-methanol-water (4:6:4:6, v/v) and (4:6:5:5, v/v). This separation yielded 4 compounds, including $28.2 \mathrm{mg}$ of arenobufagin (fraction I, 1), $13.6 \mathrm{mg}$ of bufotalin (fraction II, 2), $14.8 \mathrm{mg}$ of bufalin (fraction IV, 5) and 6.1 mg of hellebrigenin-3-hemisuberate (fraction $\mathrm{V}, \mathbf{8}$ ) with purities of 97.7, 97.0,99.5 and 96.1\%, respectively, together with the partially purified fraction III ( 3 and $\mathbf{4})$ and fraction VI ( 6 and 7). The HSCCC chromatogram is shown in Figure 2.

Subsequently, $40 \mathrm{mg}$ of partially purified fraction III and $50 \mathrm{mg}$ of partially purified fraction VI were further purified by prep-HPLC, respectively, leading to recovery of $3.5 \mathrm{mg}$ of 19-oxo-cinobufagin (3), $18.6 \mathrm{mg}$ of cinobufotalin (4), $21.4 \mathrm{mg}$ of cinobufagin (6) and 4.6 mg of resibufogenin (7) with purities of 99.0, 99.8, 99.1 and $98.5 \%$, respectively. The details of the eight bufadienolides are summarized in Table 2.

Table 2. Details of the obtained eight bufadienolides

\begin{tabular}{lccc}
\hline compound & mass & yield $(\mathrm{mg})$ & purity $(\%)$ \\
\hline 1: arenobufagin & 416.1 & 28.2 & 97.7 \\
2: bufotalin & 444.1 & 13.6 & 97.0 \\
3: 19 -oxo-cinobufagin & 456.2 & 3.5 & 99.0 \\
4: cinobufotalin & 458.1 & 18.6 & 99.8 \\
5: bufalin & 386.2 & 14.8 & 99.5 \\
6: cinobufagin & 442.2 & 21.4 & 99.1 \\
7: resibufogenin & 384.2 & 4.6 & 98.5 \\
8: hellebrigenin-3-hemisuberate & 572.3 & 6.1 & 96.1 \\
\hline
\end{tabular}

The HPLC chromatograms of the crude extract and fractions of HSCCC are depicted in Figure 3. The HPLC chromatograms of prep-HPLC for partially purified fractions III and VI are shown in Figure 4.

\section{Structural identification}

Structural identification of the 8 compounds was performed with ESI-MS and ${ }^{1} \mathrm{H}-\mathrm{NMR}$

\section{Compound 1}

ESI-MS (positive mode), $\mathrm{m} / \mathrm{z} 439.1[\mathrm{M}+\mathrm{Na}]^{+} .{ }^{1} \mathrm{H}-\mathrm{NMR}$

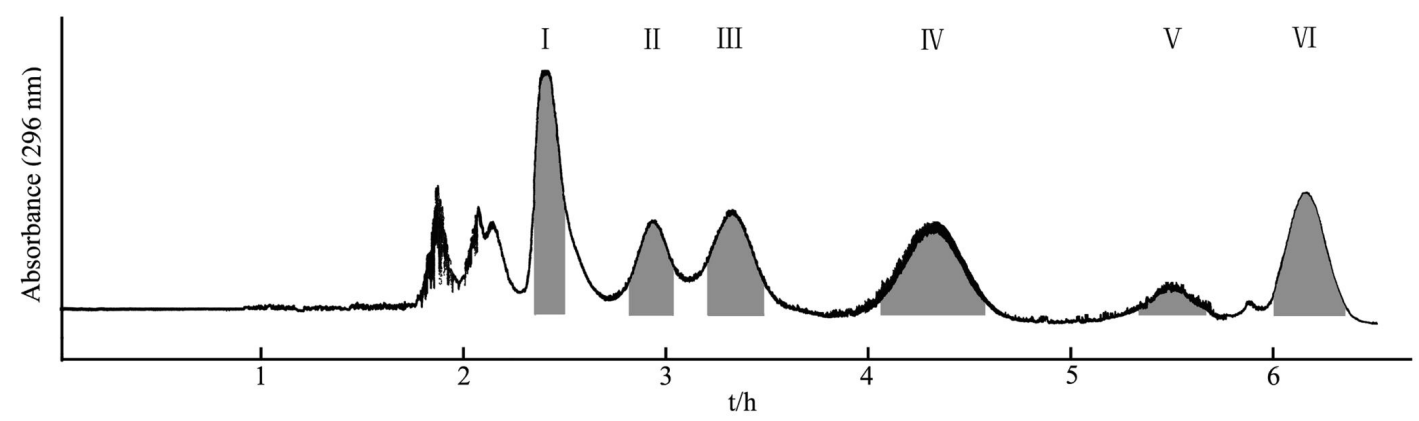

Figure 2. HSCCC chromatogram of crude extract of ChanSu. Conditions: two-phase solvent system, petroleum ether-ethyl acetate-methanol-water (4:6:4:6 and 4:6:5:5, v/v) in stepwise elution; stationary phase, upper phase of 4:6:4:6; mobile phase, lower phase of 4:6:4:6 in 0-220 min, lower phase of 4:6:5:5 in 220-400 min; flow rate, $2.0 \mathrm{~mL} / \mathrm{min}$; revolution speed, $850 \mathrm{rpm}$; detection, $296 \mathrm{~nm}$; separation temperature, $25^{\circ} \mathrm{C}$; sample size, $200 \mathrm{mg}$ crude sample dissolved in $3 \mathrm{~mL}$ of solvent $(4: 6: 4: 6, \mathrm{v} / \mathrm{v})$ consisting of $1.5 \mathrm{~mL}$ of each phase. Retention of stationary phase: $35 \%$ 
(A)

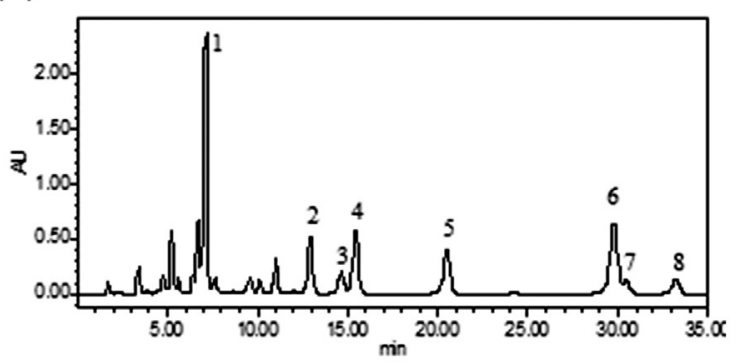

(B)
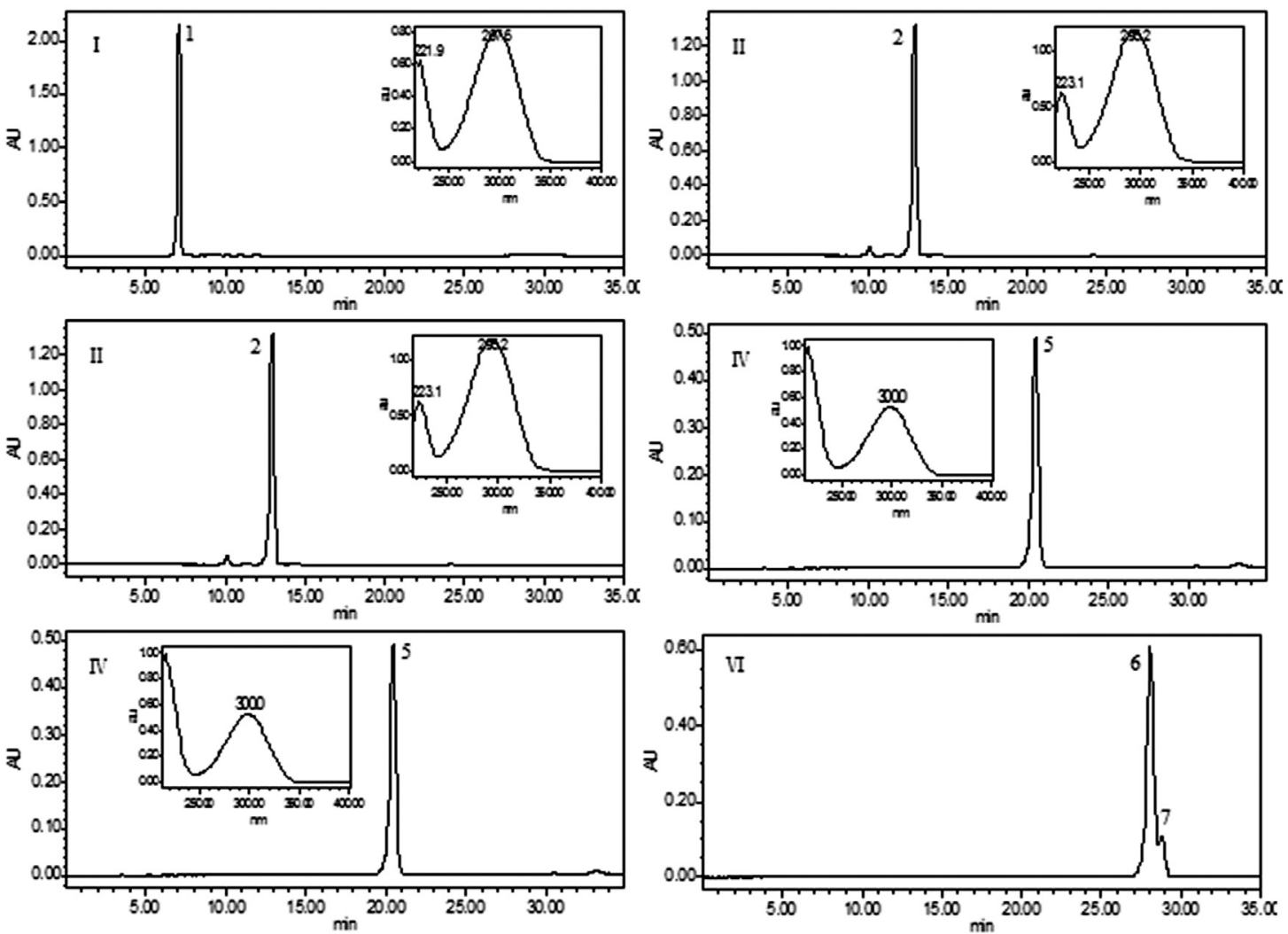

Figure 3. (A) HPLC chromatogram of the chloroform extract from ChanSu; (B) HPLC chromatograms and UV spectra of HSCCC fractions (I-VI). Conditions: column, Inertsil ODS-3 $C_{18}(250 \times 4.6 \mathrm{~mm}$, i.d., $5 \mu)$; column temperature, $25^{\circ} \mathrm{C}$; mobile phase, solvent $A$ (acetonitrile) and B $(0.3 \% \mathrm{v} / \mathrm{v}$ aqueous acetic acid) in gradient elution as follows: 0-8 min, 42\% A; 8-32 min, 42\% A-50\% A; 32-35 min, 50\% A; flow rate, $1.0 \mathrm{~mL} / \mathrm{min}$; detection, $296 \mathrm{~nm}$

(DMSO- $\left.d_{6}, 600 \mathrm{MHz}\right): 7.81(1 \mathrm{H}, \mathrm{dd}, J=9.9,1.8 \mathrm{~Hz}, \mathrm{H}-22), 7.58$ ( $1 \mathrm{H}, \mathrm{d}, J=1.8 \mathrm{~Hz}, \mathrm{H}-21), 6.33$ (1 H, d, $J=9.9 \mathrm{~Hz}, \mathrm{H}-23), 4.97$ (1 $\mathrm{H}, \mathrm{s}, 14-\mathrm{OH}), 4.49(1 \mathrm{H}, \mathrm{d}, J=4.8 \mathrm{~Hz}, 11-\mathrm{OH}), 4.27(1 \mathrm{H}, \mathrm{dd}, J=$ $11.1,4.8 \mathrm{~Hz}, \mathrm{H}-11), 4.15(1 \mathrm{H}, \mathrm{d}, J=3.0 \mathrm{~Hz}, 3-\mathrm{OH}), 3.97(1 \mathrm{H}, \mathrm{dd}$, $J=9.3,7.5 \mathrm{~Hz}, \mathrm{H}-17), 3.86(1 \mathrm{H}$, brs, H-3), 2.29 (1 H, d, $J=11.0$ $\mathrm{Hz}, \mathrm{H}-1), 1.74$ (1 H, m, H-5), 1.07 (3 H, s, $\left.\mathrm{CH}_{3}-19\right), 0.80$ (3 H, s, $\mathrm{CH}_{3}$-18). The NMR data was in agreement with those of arenobufagin in the literature. ${ }^{18}$

\section{Compound 2}

ESI-MS (positive mode), $\mathrm{m} / \mathrm{z} 467.1[\mathrm{M}+\mathrm{Na}]^{+} .{ }^{1} \mathrm{H}-\mathrm{NMR}$ (DMSO- $\left.d_{6}, 600 \mathrm{MHz}\right): 8.18(1 \mathrm{H}, \mathrm{d}, J=9.6 \mathrm{~Hz}, \mathrm{H}-22), 7.51(1 \mathrm{H}$, s, H-21), $6.20(1 \mathrm{H}, \mathrm{d}, J=9.6 \mathrm{~Hz}, \mathrm{H}-23), 5.38(1 \mathrm{H}, \mathrm{t}, J=8.9 \mathrm{~Hz}$, H-16), 4.38 (1 H, s, 14-OH), 4.19 (1 H, d, J=3.0 Hz, 3-OH), 3.89 $(1 \mathrm{H}, \mathrm{s}, \mathrm{H}-3), 2.87(1 \mathrm{H}, \mathrm{d}, J=9.0 \mathrm{~Hz}, \mathrm{H}-17), 2.61(1 \mathrm{H}, \mathrm{dd}, J=$ 15.0, 9.0 Hz, H-15), 1.78 (3 H, s, -OAc), 0.86 (3 H, s, $\left.\mathrm{CH}_{3}-19\right), 0.65$ ( $3 \mathrm{H}, \mathrm{s}, \mathrm{CH}_{3}-18$ ). The NMR data were in agreement with those of bufotalin in the literature. ${ }^{18}$

\section{Compound 3}

ESI-MS (positive mode), $m / z$ 479.2 [M+Na] $]^{+} .{ }^{1} \mathrm{H}-\mathrm{NMR}$ (DMSO- $d_{6}$, $600 \mathrm{MHz}$ ): 9.54 (1 H, s, CHO-19), 7.86 (1 H, dd, $J=9.9,1.8 \mathrm{~Hz}, \mathrm{H}-22$ ), $7.48(1 \mathrm{H}, \mathrm{d}, J=1.8 \mathrm{~Hz}, \mathrm{H}-21), 6.25(1 \mathrm{H}, \mathrm{d}, J=9.9 \mathrm{~Hz}, \mathrm{H}-23), 5.48$ $(1 \mathrm{H}, \mathrm{d}, J=9.6 \mathrm{~Hz}, \mathrm{H}-16), 4.43(1 \mathrm{H}, \mathrm{d}, J=3.0 \mathrm{~Hz}, 3-\mathrm{OH}), 3.92(1 \mathrm{H}$, brs, H-3), 3.76 (1 H, s, H-15), 2.88 (1 H, d, J=9.6 Hz, H-17), 1.82 (3 $\mathrm{H}, \mathrm{s},-\mathrm{OAc}), 0.76\left(3 \mathrm{H}, \mathrm{s}, \mathrm{CH}_{3}-18\right)$. The NMR data were in agreement with those of 19-oxo-cinobufagin in the literature. ${ }^{18}$

\section{Compound 4}

ESI-MS (positive mode), $\mathrm{m} / \mathrm{z} 481.1[\mathrm{M}+\mathrm{Na}]^{+} .{ }^{1} \mathrm{H}-\mathrm{NMR}$ (DMSO- $d_{6}, 600 \mathrm{MHz}$ ): 7.81 (1 H, dd, $\left.J=9.6,1.5 \mathrm{~Hz}, \mathrm{H}-22\right), 7.47$ $(1 \mathrm{H}, \mathrm{d}, J=1.5 \mathrm{~Hz}, \mathrm{H}-21), 6.24(1 \mathrm{H}, \mathrm{d}, J=9.6 \mathrm{~Hz}, \mathrm{H}-23), 5.47$ (1 $\mathrm{H}, \mathrm{d}, J=9.6 \mathrm{~Hz}, \mathrm{H}-16), 5.22(1 \mathrm{H}, \mathrm{s}, 3-\mathrm{OH}), 4.58(1 \mathrm{H}, \mathrm{s}, 5-\mathrm{OH})$, $4.01(1 \mathrm{H}, \mathrm{s}, \mathrm{H}-3), 3.75(1 \mathrm{H}, \mathrm{s}, \mathrm{H}-15), 2.87(1 \mathrm{H}, \mathrm{d}, J=9.6 \mathrm{~Hz}$, $\mathrm{H}-17), 1.82$ (3 H, s, -OAc), $0.86\left(3 \mathrm{H}, \mathrm{s}, \mathrm{CH}_{3}-19\right), 0.70\left(3 \mathrm{H}, \mathrm{s}, \mathrm{CH}_{3}-\right.$ 18). The NMR data were in agreement with those of cinobufotalin in the literature. ${ }^{18}$ 

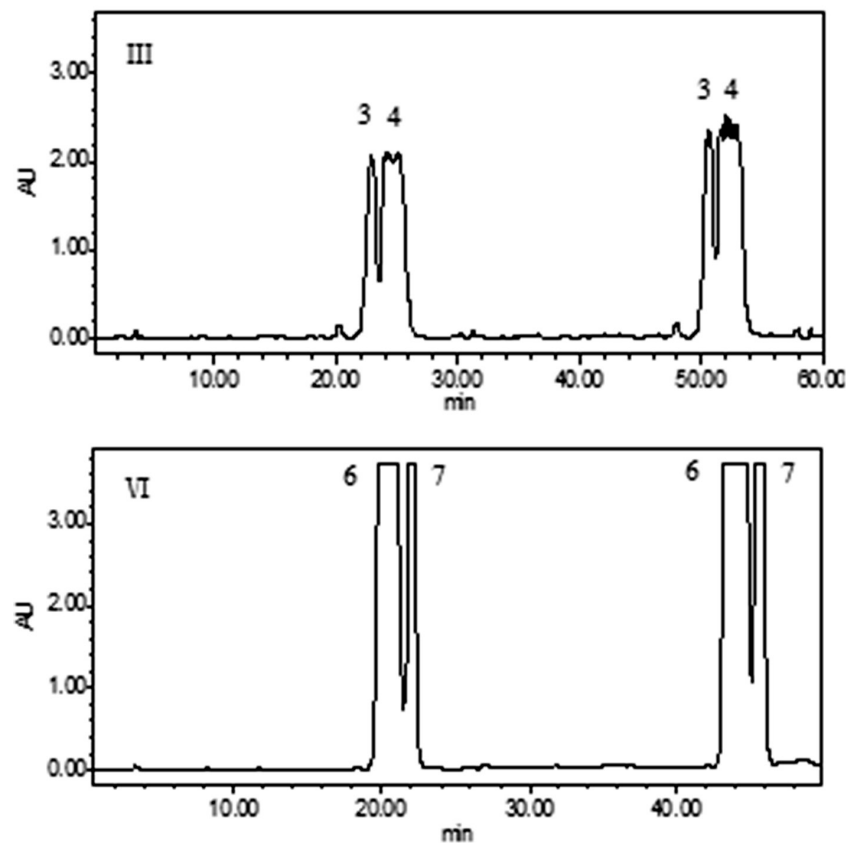

Figure 4. Prep-HPLC chromatograms of fraction III and fraction VI. Conditions: column, YMC-Pack ODS-A $(250 \times 10 \mathrm{~mm}$, i.d., $5 \mu)$; flow rate, 2.5 mL/min; UV wavelength, $296 \mathrm{~nm}$; mobile phase for fraction III, acetonitrile-0.3\% aqueous acetic acid (35:65, v/v); mobile phase for fraction VI, acetonitrile-0.3\% aqueous acetic acid (45:55, v/v). 3: 19-oxo-cinobufagin; 4: cinobufotalin; 6: cinobufagin; 7: resibufogenin

\section{Compound 5}

ESI-MS (positive mode), $\mathrm{m} / z, 409.2[\mathrm{M}+\mathrm{Na}]^{+} .{ }^{1} \mathrm{H}-\mathrm{NMR}$ (DMSO- $d_{6}, 600 \mathrm{MHz}$ ): 7.93 (1 H, dd, $\left.J=9.6,2.0 \mathrm{~Hz}, \mathrm{H}-22\right), 7.52$ $(1 \mathrm{H}, \mathrm{d}, J=2.0 \mathrm{~Hz}, \mathrm{H}-21), 6.29(1 \mathrm{H}, \mathrm{d}, J=9.6 \mathrm{~Hz}, \mathrm{H}-23), 4.18$ (1 H, brs, 3-OH), 4.12 (1 H, brs, 14-OH), 3.84 (1 H, brs, H-3), 2.43 (1 $\mathrm{H}, \mathrm{m}, \mathrm{H}-17), 0.86$ (3 H, s, $\left.\mathrm{CH}_{3}-19\right), 0.59$ (3 H, s, $\mathrm{CH}_{3}-18$ ). The NMR data were in agreement with those of bufalin in the literature. ${ }^{12}$

\section{Compound 6}

ESI-MS (positive mode), $\mathrm{m} / \mathrm{z}, 465.2[\mathrm{M}+\mathrm{Na}]^{+} .{ }^{1} \mathrm{H}-\mathrm{NMR}$ (DMSO- $\left.d_{6}, 600 \mathrm{MHz}\right) 7.80(1 \mathrm{H}, \mathrm{d}, J=10.0 \mathrm{~Hz}, \mathrm{H}-22), 7.47(1 \mathrm{H}$, s, H-21), $6.24(1 \mathrm{H}, \mathrm{d}, J=10.0 \mathrm{~Hz}, \mathrm{H}-23), 5.48(1 \mathrm{H}, \mathrm{d}, J=9.6 \mathrm{~Hz}$, H-16), 4.21 (1 H, brs, 3-OH), 3.89 (1 H, brs, H-3), 3.75 (1 H, s, H-15), $2.87(1 \mathrm{H}, \mathrm{d}, J=9.6 \mathrm{~Hz}, \mathrm{H}-17), 1.82(3 \mathrm{H}, \mathrm{s},-\mathrm{OAc}), 0.90(3 \mathrm{H}, \mathrm{s}$, $\left.\mathrm{CH}_{3}-19\right), 0.71$ (3 H, s, $\left.\mathrm{CH}_{3}-18\right)$. The NMR data were in agreement with those of cinobufagin in the literature. ${ }^{19}$

\section{Compound 7}

ESI-MS (positive mode), $\mathrm{m} / \mathrm{z} 407.2[\mathrm{M}+\mathrm{Na}]^{+} .{ }^{1} \mathrm{H}-\mathrm{NMR}$ (DMSO- $d_{6}, 600 \mathrm{MHz}$ ): 7.77 (1 H, dd, $\left.J=9.6,2.5 \mathrm{~Hz}, \mathrm{H}-22\right), 7.53$ $(1 \mathrm{H}, \mathrm{d}, J=2.5 \mathrm{~Hz}, \mathrm{H}-21), 6.26(1 \mathrm{H}, \mathrm{d}, J=9.6 \mathrm{~Hz}, \mathrm{H}-23), 4.21(1$ H, brs, H-3), 3.59 (1 H, s, H-15), 2.52 (2 H, m, H-16), 0.91 (3 H, s, $\left.\mathrm{CH}_{3}-19\right), 0.68$ (3 H, s, $\left.\mathrm{CH}_{3}-18\right)$. The NMR data were in agreement with those of resibufogenin in the literature. ${ }^{20}$

\section{Compound 8}

ESI-MS (positive mode), $\mathrm{m} / \mathrm{z} 595.3[\mathrm{M}+\mathrm{Na}]^{+} .{ }^{1} \mathrm{H}-\mathrm{NMR}$ (DMSO- $\left.d_{6}, 600 \mathrm{MHz}\right): 11.95$ (1 H, s, -COOH), 10.46 (1 H, s, CHO19), 8.21 ( $1 \mathrm{H}, \mathrm{dd}, J=9.6,2.5 \mathrm{~Hz}, \mathrm{H}-22), 7.43(1 \mathrm{H}, \mathrm{d}, J=2.5 \mathrm{~Hz}$, H-21), 6.35 (1 H, d, J = 9.6 Hz, H-23), 5.35 (1 H, brs, H-3), 2.50 (1 $\mathrm{H}, \mathrm{m}, \mathrm{H}-17), 0.87$ ( $\left.3 \mathrm{H}, \mathrm{s}, \mathrm{CH}_{3}-18\right)$. The NMR data were in agreement with those of hellebrigenin-3-hemisuberate in the literature. ${ }^{21}$

\section{CONCLUSION}

The present study demonstrated a high-efficiency method for the separation and purification of bufadienolides from $\mathrm{ChanSu}$ by HSCCC combined with prep-HPLC. Eight bufadienolides, including arenobufagin (1), bufotalin (2), 19-oxo-cinobufagin (3), cinobufotalin (4), bufalin (5), cinobufagin (6), resibufogenin (7) and hellebrigenin-3-hemisuberate $(\mathbf{8})$ were obtained. Their purities were 97.7, 97.0, 99.0, 99.8, 99.5, 99.1, 98.5 and $96.1 \%$, respectively. The present study proved that the combination of HSCCC and prep-HPLC is a very useful, powerful and rapid technique for the isolation and purification of as many bufadienolides as possible at high purities from ChanSu. Meanwhile, it also demonstrated that the combined methods of HSCCC and prep-HPLC can be employed to prepare as many bioactive components as possible from natural products.

\section{ACKNOWLEDGEMENTS}

Financial support from the Natural Science Foundation of China (21202094), the Natural Science Foundation of Shandong Province (ZR2012HQ020, BS2009SW047), the special foundation of Taishan Overseas Distinguished experts and scholars, the Young Science and Technology Star Program of Jinan (20110315) and the Science and Technology Program of ShanDong Academy of Sciences (201107) are gratefully acknowledged.

\section{REFERENCES}

1. The State Pharmacopoeia Commission of China; Pharmacopoeia of China, Chemical Industry Press: Beijing, 2010, p. 360.

2. Cheng, G.; Chin. Trad. Herb. Drugs 2001, 32, 184.

3. Liu, J.; Zhang, D.; Li, Y.; Ye, W.; J. Int. Pharm. Res. 2009, 36, 115.

4. Yeh, J. Y.; Huang, W. J.; Kan, S. F.; Wang, P. S.; The Prostate 2003, 54, 112.

5. Zhang, L. S.; Nakaya, K.; Yoshida, T.; Kuroiwa, Y.; Biochem. Biophys. Res. Commun. 1991, 178, 686.

6. Qiao, L.; Duan, W.; Yao, Y.; Chen, H.; Liu, T.; Pei, Y.; J. Shenyang Pharm. Univ. 2007, 24, 611

7. Ma, X.; Zhang, B.; Deng, S.; Wang, C.; Shu, X.; Huang, Sh.; Diao, Y.; Zhang, H.; Zhen, Y.; Prog. Mod. Biomed. 2009, 9, 3519.

8. Chen, L. J.; Games, D. E.; Jones, J.; J. Chromatogr., A 2003, 988, 95.

9. Rinaldo, D.; Silva, M. A.; Rodrigues, C. M.; Calvo, T. R.; Sannomiya, M.; dos Santos, L. C.; Kushima, H.; Hiruma-Lima, C. A.; Brito, A. R. M. S.; Vilegas, W.; Quim. Nova 2006, 29, 947.

10. Almeida, M. R.; Leitão, G. G.; Silva, B. V.; Barbosa, J. P.; Pinto, A. C.; J. Braz. Chem. Soc. 2010, 21, 764.

11. Wang, D.; Lin, Y.; Lin, X.; Geng, Y.; Wang, X.; Zhang, J.; Qiu, J.; Quim. Nova 2012, 35, 337.

12. Li, J.; Ma, X.; Li, F.; Wang, J.; Chen, H.; Wang, G.; Lv, X.; Sun, C.; Jia, J.; J. Sep. Sci. 2010, 33, 1325.

13. Zhu, L.; Li, H.; Liang, Y.; Wang, X.; Xie, H.; Zhang, T.; Ito, Y.; Sep. Purif. Technol. 2009, 70, 147.

14. Wang, D.; Fang, L.; Wang, X.; Qiu, J.; Huang, L.; Quim. Nova 2011, 34, 804.

15. Peng, J.; Fan, G.; Wu, Y.; J. Chromatogr., A 2005, 1091, 89.

16. Foucault, A. P.; Chevolot, L.; J. Chromatogr., A 1998, 808, 3.

17. Oka, H.; Harada, K.; Suzuki, M.; Ito, Y.; J. Chromatogr., A 2000, 903, 93.

18. Ye, M.; Guo, H.; Guo, H.; Han, J.; Guo, D.; J. Chromatogr., B: Anal. Technol. Biomed. Life Sci. 2006, 838, 86.

19. Ma, X.; Xin, X.; Liu, K.; Han, J.; Guo, D.; J. Nat. Prod. 2008, 71, 1268.

20. Verpoorte, R.; Phan, Q. K.; Baerheim, S. A.; J. Nat. Prod. 1980, 43, 347.

21. Zhang, Y.; Qiu, Y.; Chen, J.; Bo, K.; Jiang, Y.; Pei, Y.; J. Shenyang Pharm. Univ. 2007, 24, 484. 